\title{
Sponsoring Institutions with Five or Fewer Residency Programs Produce a Larger Proportion of General Internists and Family Physicians
}

\author{
Sarab Hemeida, MD, Kathleen Klink, MD, Andrew Bazemore, MD, MPH, \\ Stephen Petterson, PhD, and Lars Peterson, $M D, P h D$
}

Policymakers are increasingly interested in addressing the US primary care physician shortage and achieving measurable accountability for the products of the nation's $\$ 15$ billion investment in graduate medical education (GME). Using one such measure, we found that sponsoring institutions (SIs) with $\leq 5$ residency programs produce a higher percentage of general internists and family physicians than larger SIs. (J Am Board Fam Med 2016;29:301-302.)

Keywords: Family Practice, Health Policy, Primary Health Care

The Balanced Budget Act of 1997 restricted Centers for Medicare and Medicaid-funded positions for existing SIs, known as "the cap." ${ }^{1}$ Despite federal cost containment, the number of positions has expanded, ${ }^{2}$ favoring subspecialty expansion at a significantly higher rate than primary care. ${ }^{3}$

Since smaller SIs provide limited exposure to specialty medicine and a potentially wider scope of practice during residency training, we hypothesized that they might also produce more primary care physicians. Practicing general internists and family physicians were matched with the size of the SI where they trained, and the SIs were grouped by the number of residencies they sponsor. ${ }^{4}$ Physicians were identified through the American Medical Association Masterfile and its GME historic supplement. We included those who completed a residency between 2006 and 2008 and determined

This article was externally peer reviewed.

Submitted 27 March 2015; revised 29 February 2016; accepted 8 March 2016.

From the Department of Family Medicine, University of Colorado, Denver (SH); the Robert Graham Center, Washington, DC (KK, AB, SP); and American Board of Family Medicine, Lexington, KY (LP).

Funding: none.

Conflict of interest: LP is affiliated with the American Board of Family Medicine.

Corresponding author: Sarah Hemeida, MD, The Robert Graham Center, Eugene S. Farley Health Policy Center, Denver Health Hospital, 1022 Pontiac St, Denver, CO 80220 (E-mail: sarah.hemeida@dhha.org). whether they practiced primary care in 2014, intentionally allowing time for graduates who pursued fellowships to complete subspecialty training.

SIs with $\leq 5$ residencies produce nearly $40 \%$ the national primary care workforce. While small SIs vastly outnumber larger institutions, only $14 \%$ of all residents graduated from small SIs. Thus the key finding is that a significantly higher percentage of internal medicine (IM) graduates will remain working in primary care if they trained at a small SI. Over $56 \%$ of IM graduates from small SIs (1-5 residencies) pursue generalist careers compared with graduates from large SIs (with $\geq 41$ residencies), where only $28 \%$ practice primary care $(P<.01)$. Figure 1 .

This simple association reminds us that the majority of our primary care workforce comes not from the more traditional behemoths of GME, but smaller, often community-based hospital training sites, and that these sites produce disproportionate numbers of general internists, whose numbers are steeply declining nationally. It is understood that residents who plan to subspecialize often intentionally attend large SIs where they will benefit from exposure to the fellowship of their choice. These same large institutions often provide primary care training tracks. Despite this, small SIs continue to produce a larger percentage of IM graduates who practice primary care. The majority of GME funding goes to large SIs, yet they yield the smallest numbers of family physicians and an even smaller number of general internists. It is 
Figure 1. Residents eventually practicing in primary care by number of training specialties within a sponsoring institution.

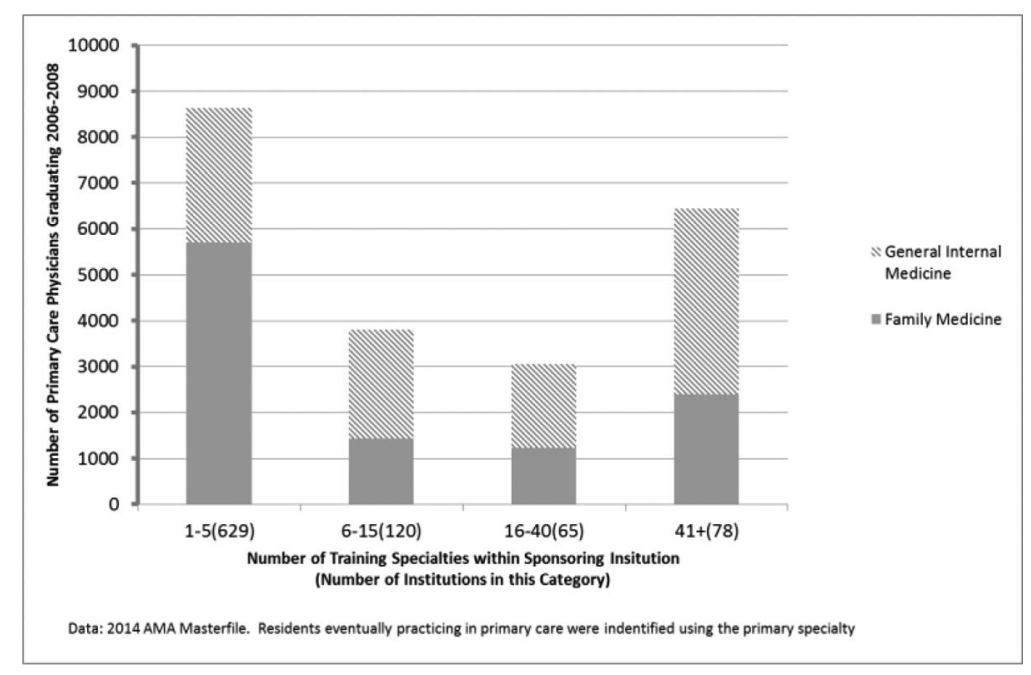

crucial to understand the influences that may encourage undecided IM residents to remain in primary care. Secure and sufficient funding for small SIs is a key opportunity to increase the national primary care workforce.

\section{References}

1. Balanced Budget Act of 1997, HR 2015, 105th Cong, 1st Sess (1997), \$4623.

2. Council on Graduate Medical Education. Council on Graduate Medical Education twentieth report. Advancing primary care. Rockville, MD: Health Resources and Services Administration; 2010. Available from: http://www.hrsa.gov/advisorycommittees/ bhpradvisory/cogme/reports/twentiethreport.pdf. Accessed March 22, 2016.

3. Salsberg E, Rockey PH, Rivers KL, Brotherton S, Jackson G. US residency training before and after the 1997 Balanced Budget Act. JAMA 2008;300: 1174-80.

4. Chen C, Petterson S, Phillips RL, Mullan F, Bazemore A, O'Donnell SD. Toward graduate medical education (GME) accountability: measuring the outcomes of GME institutions. Acad Med 2013;88:1267-80. 